\title{
Development of Neutral pH-Responsive Microgels by Tuning Cross-Linking Conditions
}

\author{
Satoshi Okada ${ }^{1,2,3, * \mathbb{C}}$, Satoko Takayasu ${ }^{3}$, Shunsuke Tomita ${ }^{3}{ }^{\mathbb{D}}$, Yoshio Suzuki ${ }^{3}$ and \\ Shinya Yamamoto ${ }^{4}(\mathbb{C}$ \\ 1 Laboratory for Chemistry and Life Science Institute of Innovative Research, Tokyo Institute of Technology, \\ 4259 Nagatsuta-cho, Midori-ku, Yokohama, Kanagawa 226-8503, Japan \\ 2 JST, PRESTO, 4259 Nagatsuta-cho, Midori-ku, Yokohama, Kanagawa 226-8503, Japan \\ 3 Health and Medical Research Institute, National Institute of Advanced Industrial Science and \\ Technology (AIST), 1-1-1 Higashi, Tsukuba, Ibaraki 305-8566, Japan; s-takayasu@aist.go.jp (S.T.); \\ s.tomita@aist.go.jp (S.T.); suzuki-yoshio@aist.go.jp (Y.S.) \\ 4 Human Informatics and Interaction Research Institute, National Institute of Advanced Industrial Science \\ and Technology (AIST), 1-1-1 Umezono, Tsukuba, Ibaraki 305-8568, Japan; yamamoto-s@aist.go.jp \\ * Correspondence: sokada@res.titech.ac.jp; Tel.: +81-45-924-5279
}

Received: 26 May 2020; Accepted: 12 June 2020; Published: 14 June 2020

\begin{abstract}
Polymer microgels that respond in a range of neutral $\mathrm{pH}$ can be useful for the development of molecular imaging tools and drug-delivery carriers. Here, we describe a simple approach in developing microgels that undergo volume phase transitions and substantial nuclear magnetic resonance (NMR) relaxometric changes within a narrow $\mathrm{pH}$ range of 6.4 to 7.4. The $\mathrm{pH}$-responsive microgels were synthesized using methacrylic acid and a series of ethylene glycol dimethacrylate cross-linkers with repeating units of ethylene glycol that range from one to four. NMR relaxometry demonstrated that the transverse relaxation time $\left(T_{2}\right)$ of a suspension containing microgels that were cross-linked with diethylene glycol dimethacrylate sharply decreases at the $\mathrm{pH}$ where volume phase transition occurs. The polymer microgels cross-linked with 40 and $45 \mathrm{~mol} \%$ of diethylene glycol dimethacrylate caused about $50 \% \mathrm{~T}_{2}$ reduction with decreasing $\mathrm{pH}$ from 6.8 to 6.4. These results demonstrated that responses of microgels to a range of neutral $\mathrm{pH}$ can be easily tuned by using appropriate cross-linkers with certain cross-linking degree. This approach can be useful in developing highly sensitive molecular sensors for magnetic resonance imaging (MRI) of tissue $\mathrm{pH}$ values.
\end{abstract}

Keywords: pH-responsive microgels; NMR relaxation time; volume phase transition; MRI

\section{Introduction}

Magnetic resonance spectroscopy has revealed disorders of acid-base balance in pathologic tissues, although its spatial and temporal resolution is inferior to conventional magnetic resonance imaging (MRI) [1-3]. MRI contrast agent-based $\mathrm{pH}$ sensors can be powerful tools for highly sensitive $\mathrm{pH}$ imaging [4-10]; however, it is still difficult to make contrast agents respond within a narrow range of physiological $\mathrm{pH}$. The detectability of the $\mathrm{pH}$ difference between 6.4 and 7.4 is important for the identification of diseases such as cancer, kidney disease, and cardiac ischemia because these $\mathrm{pH}$ values are consistent with the $\mathrm{pH}$ values observed in pathological and normal tissues, respectively [11,12]. To develop neutral $\mathrm{pH}$-responsive MRI sensors, synthetic cross-linked polymers were considered as promising materials because their volume phase transitions cause significant changes in the transverse relaxation time $\left(T_{2}\right)$ of water [13-15]. The shrunken state of cross-linked polymer microgels enhances $T_{2}$ relaxation of solvent water protons more efficiently than its swollen state. Precipitation polymerization is a simple way to synthesize monodisperse microgels, although there are few reports about neutral 
$\mathrm{pH}$-responsive polymers synthesized by this method [16-21]. Here, we present a simple approach in developing microgels that undergo volume phase transition in a narrow range of physiological $\mathrm{pH}$ and their application to neutral $\mathrm{pH}$ sensors for nuclear magnetic resonance (NMR)/MRI.

\section{Materials and Methods}

\subsection{Reagents}

Methacrylic acid (MAA), N,N'-methylenebisacrylamide (MBAA), ethylene glycol dimethacrylate (EGDMA), 2,2'-azobisisobutyronitrile (AIBN), and acetonitrile were obtained from FUJIFILM Wako Pure Chemical Co. (Osaka, Japan). Diethylene glycol dimethacrylate (DEGDMA), triethylene glycol dimethacrylate (TEGDMA), and tetraethylene glycol dimethacrylate (TETEGDMA) were obtained from Tokyo Chemical Industry Co., Ltd. (Tokyo, Japan). All of the reagents were of the best grade available. The cross-linkers were purified with active basic aluminum oxide 60 (Sigma-Aldrich Co. LLC., St. Louis, MO, USA) to remove polymerization inhibitors.

\subsection{Synthesis}

The cross-linked polymer microgels were synthesized by precipitation polymerization $[19,20]$. In a typical synthesis of $20 \mathrm{~mol} \%$ cross-linked polymers, MAA (490 mg, $5.69 \mathrm{mmol}$ ), a cross-linker $(1.42 \mathrm{mmol}$ ), and AIBN initiator ( $13 \mathrm{mg}, 0.08 \mathrm{mmol}, 1 \mathrm{~mol} \%$ of total monomers) were dissolved in $80 \mathrm{~mL}$ of acetonitrile. The mixture was refluxed under nitrogen for $1 \mathrm{~h}$. Then, the mixture was centrifuged at $20,000 \times g$ and washed by acetonitrile three times. The white precipitate was dried in vacuo to obtain 100-200 mg of polymers. To synthesize other polymers with different cross-linking degree, the molar ratio of the cross-linker to MAA was changed accordingly; the total mole of the cross-linker and MAA was kept at $7.12 \mathrm{mmol}$ in $80 \mathrm{~mL}$ of acetonitrile. The stoichiometric ratio of the cross-linker to the total monomers was almost consistent with the cross-linking degree calculated from elemental analysis, except for the MBAA-based polymer, where the cross-linking degree was $30 \mathrm{~mol} \%$.

\subsection{Nuclear Magnetic Resonance (NMR) Relaxometry}

Longitudinal relaxation time $\left(T_{1}\right)$ and transverse relaxation time $\left(T_{2}\right)$ were measured using a Spinsolve ULTRA $43 \mathrm{MHz}^{1} \mathrm{H}-\mathrm{NMR}$ (Magritek Ltd., Wellington, New Zealand) in $500 \mu \mathrm{L}$ of $100 \mathrm{mM}$ phosphate buffer (see Supplementary Text about NMR relaxation). The inversion-recovery (IR) and Carr-Purcell-Meiboom-Gill (CPMG) pulse sequences were used to measure $T_{1}$ and $T_{2}$, respectively. The parameters in the inversion recovery (IR) pulse sequence were as follows: number of scans $=2$, acquisition time $=1.6 \mathrm{~s}$, repetition time $=7 \mathrm{~s}$, maximum inversion time $=5 \mathrm{~s}$, number of steps $=21$. The parameters in the CPMG sequence pulse sequence were as follows: number of scans $=4$, acquisition time $=0.8 \mathrm{~s}$, repetition time $=4 \mathrm{~s}, C P M G$ echo time $=1 \mathrm{~ms}$, final echo time $=2 \mathrm{~s}$, number of steps $=20$.

\subsection{Magnetic Resonance Imaging (MRI)}

MRI was performed using MRmini SA1506 scanner (DS Pharma Biomedical Co., Ltd., Osaka, Japan) equipped with a $1.5 \mathrm{~T}$ permanent magnet and a radiofrequency (RF) coil of $38.5 \mathrm{~mm}$ inner diameter. A multislice spin echo pulse sequence was used to obtain $T_{2}$-weighted images with parameters including the number of averages $=1$, matrix size $=128 \times 256$, field of view $=2 \mathrm{~cm} \times 4 \mathrm{~cm}$, slice thickness $=2 \mathrm{~mm}$, repetition time $(\mathrm{TR})=2000 \mathrm{~ms}$, and echo time $(\mathrm{TE})=150 \mathrm{~ms}$.

\subsection{Transmission Electron Microscopy (TEM)}

A $5 \mu \mathrm{L}$ Milli-Q water containing $0.01 \mathrm{wt} \%$ cross-linked polymer was dropped on a formvar-coated grid stabilized with evaporated carbon film (STEM Co., Ltd., Tokyo, Japan) and then dried under vacuum. TEM images were captured using JEM-2100F (JEOL Ltd., Tokyo, Japan) operated at $200 \mathrm{kV}$. 


\section{Results and Discussion}

\subsection{Synthesis of Cross-Linked Polymer Microgels}

We expected that the phase transition behavior of microgels would be tuned by changing the molar ratio of a cross-linker to an ionic monomer as well as the type of cross-linker. On the basis of this premise, we synthesized poly(methacrylic acid) cross-linked with a series of ethylene glycol dimethacrylate with repeating units ranging from one to four by precipitation polymerization (Scheme 1).
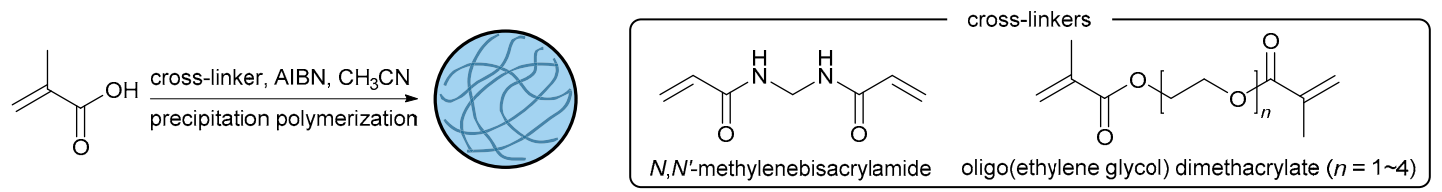

Scheme 1. Synthesis of the $\mathrm{pH}$-responsive microgels.

The synthesized polymer microgels were divided into two groups based on the type of cross-linker used and the degree of cross-linking (Table 1). The microgels in Group 1 were synthesized using five different types of cross-linkers: $N, N^{\prime}$-methylenebisacrylamide (MBAA), ethylene glycol dimethacrylate (EGDMA), diethylene glycol dimethacrylate (DEGDMA), triethylene glycol dimethacrylate (TEGDMA), and tetraethylene glycol dimethacrylate (TETEGDMA). In Group 1, the molar ratio of the cross-linkers to the total monomers was fixed at $20 \mathrm{~mol} \%$ in reaction stoichiometry, except for the EGDMA-based microgel as it produced low yield at the same mol\%. The polymer cross-linked by MBAA showed a slightly higher degree of cross-linking than its stoichiometric ratio, whereas the cross-linking degree of the other microgels was almost consistent with their corresponding ratios. The microgels in Group 2 were synthesized using the DEGDMA cross-linker only but with different cross-linking degrees of 20, 30, 40, and $45 \mathrm{~mol} \%$. The $20 \mathrm{~mol} \%$ DEGDMA-based microgel belongs to both groups. We tried to synthesize the microgels cross-linked by $30 \mathrm{~mol} \%$ of TEGDMA and TETEGDMA but they formed a huge aggregate during reaction. The reaction mixture using longer cross-linkers and larger amounts of cross-linkers became more turbid. This indicates the formation of highly polymerized compounds due to the high reactivity of the cross-linkers [22].

Table 1. The groups of poly(methacrylic acid) based on different types of cross-linkers and different degrees of cross-linking.

\begin{tabular}{ccc}
\hline Group & Cross-Linker and Repeating Unit $(n)$ & Cross-Linking Degree $(\mathbf{m o l} \mathbf{\%})$ \\
\hline 1 & MBAA & 30 \\
1 & EGDMA $(n=1)$ & 40 \\
1,2 & DEGDMA $(n=2)$ & 20 \\
1 & TEGDMA $(n=3)$ & 20 \\
1 & TETEGDMA $(n=4)$ & 20 \\
2 & DEGDMA $(n=2)$ & 30 \\
2 & DEGDMA $(n=2)$ & 40 \\
2 & DEGDMA $(n=2)$ & 45 \\
\hline
\end{tabular}

\subsection{TEM Images and Volume Phase Transition Behaviors}

TEM showed that the cross-linked polymers in both groups have a uniform and spherical structure (Figure 1). We were unable to obtain clear images of the MBAA-based microgel due to difficulties in focusing. The mean diameters of Group 1 microgel particles increased from $120 \mathrm{~nm}$ up to $330 \mathrm{~nm}$ as the length of the cross-linkers increased (Figure 1a-d and Table S1). The microgels with longer cross-linkers also showed a clearer outline. The TEM images of Group 2 microgel particles show that a higher degree of cross-linking results in a larger particle size from $160 \mathrm{~nm}$ to $580 \mathrm{~nm}$ and a more distinct structure (Figure 1b,e-g and Table S1). Interestingly, a core-shell structure was observed in 
all the polymers. This might be due to an uneven distribution of cross-linking density caused by the reactivity difference between MAA and the cross-linkers [22,23].
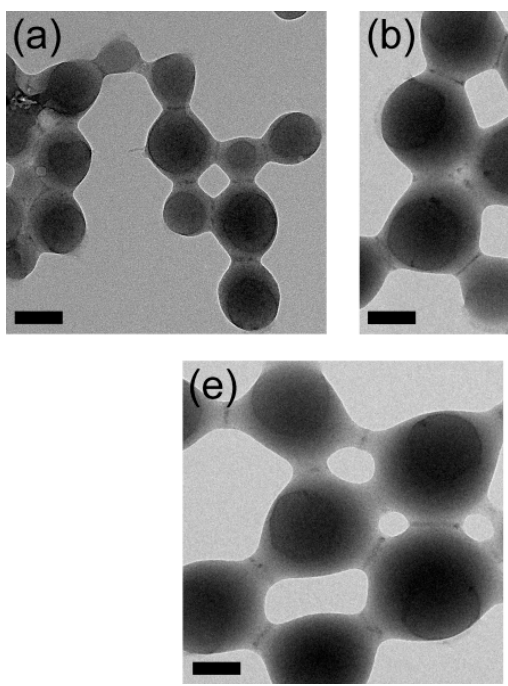

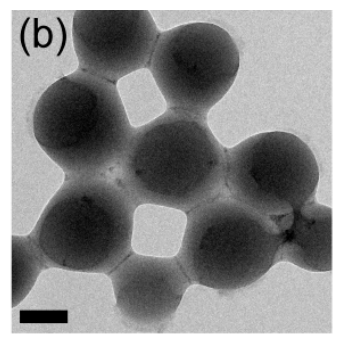

(f)

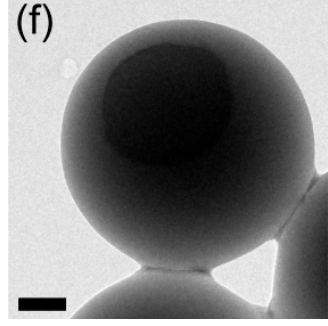

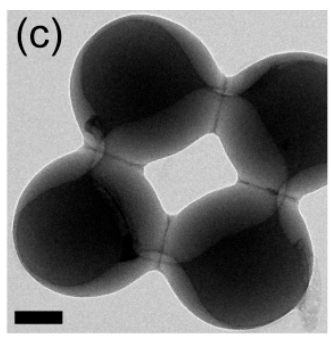

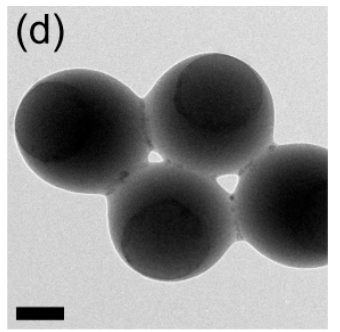

(g)

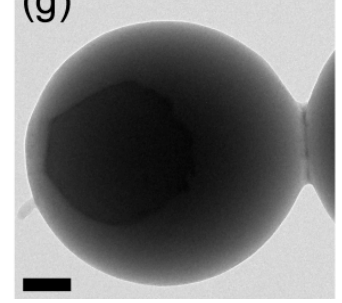

Figure 1. Transmission electron microscopy (TEM) images of poly(methacrylic acid) cross-linked with (a) $40 \mathrm{~mol} \%$ EGDMA, (b) 20 mol\% DEGDMA, (c) 20 mol\% TEGDMA, (d) 20 mol\% TETEGDMA, (e) $30 \mathrm{~mol} \%$ DEGDMA, (f) $40 \mathrm{~mol} \%$ DEGDMA, and (g) $45 \mathrm{~mol} \%$ DEGDMA. Scale bars $=100 \mathrm{~nm}$.

A volume phase transition behavior was confirmed by testing suspensions with $0.50 \mathrm{wt} \%$ microgel concentration against $100 \mathrm{mM}$ phosphate buffer with $\mathrm{pH}$ ranging from 6.0 to 7.4 at 0.2 increments (Figure 2). In Group 1, the MBAA- and EGDMA-based microgel suspensions were turbid throughout the $\mathrm{pH}$ range (Figure $2 \mathrm{a}, \mathrm{b}$ ), whereas the other microgel suspensions were transparent (Figure 2c-e). In contrast, a phase transition within the $\mathrm{pH}$ range of 6.2 to 6.6 , with $0.2 \mathrm{pH}$ differences, was clearly visible in Group 2 (Figure 2f-h). The transition $\mathrm{pH}$ of the 30, 40, and $45 \mathrm{~mol} \%$ DEGDMA-based microgels were 6.2, 6.6, and 6.6, respectively; however, the $40 \mathrm{~mol} \%$ DEGDMA-based microgel showed an intermediate state at $\mathrm{pH} 6.6$ (Figure $2 \mathrm{~g}$ ).

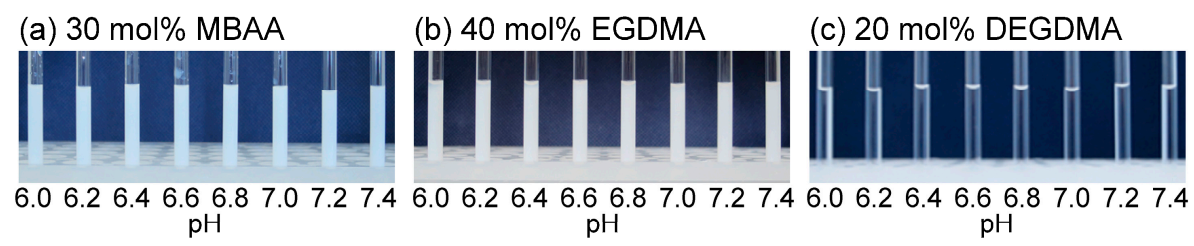

(d) 20 mol\% TEGDMA

(e) 20 mol\% TETEGDMA

(f) 30 mol\% DEGDMA

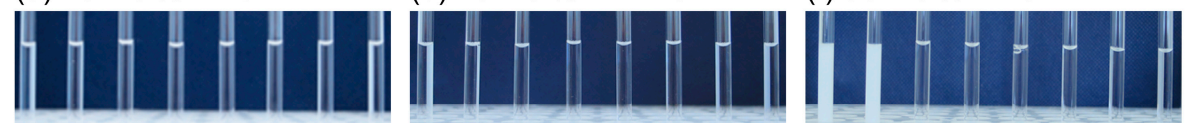

$6.06 .26 .46 .6 \quad 6.87 .07 .27 .4 \quad 6.06 .26 .46 .6 \quad 6.87 .07 .27 .4 \quad 6.06 .26 .46 .6 \quad 6.87 .07 .27 .4$ $\mathrm{pH}$ $\mathrm{pH}$ $\mathrm{pH}$

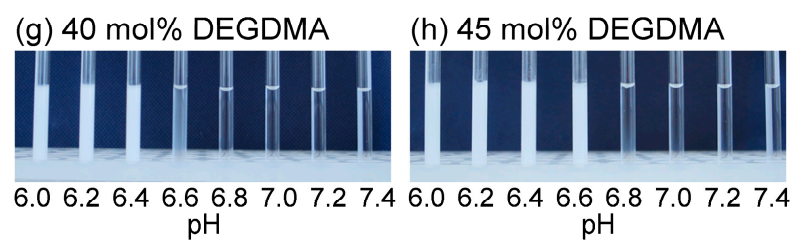

Figure 2. The phase transition behaviors of the poly(methacrylic acid) cross-linked with (a) $30 \mathrm{~mol} \%$ MBAA, (b) 40 mol\% EGDMA, (c) 20 mol\% DEGDMA, (d) 20 mol\% TEGDMA, (e) 20 mol\% TETEGDMA, (f) $30 \mathrm{~mol} \%$ DEGDMA, (g) $40 \mathrm{~mol} \%$ DEGDMA, and (h) 45 mol\% DEGDMA in $100 \mathrm{mM}$ phosphate buffer, $\mathrm{pH} 6.0$ to 7.4 with 0.2 increments at room temperature. [microgel] $=0.50 \mathrm{wt} \%$. 
Figure 3 shows the volume phase transition behaviors of the $40 \mathrm{~mol} \%$ DEGDMA-based microgel suspensions in different concentrations ( 0.10 to $0.50 \mathrm{wt} \%$ ). The suspensions became less turbid with decreasing concentration; however, the transition at $\mathrm{pH} 6.6$ did not change, indicating that the microgel function could be kept relatively stable even if they were diluted after injection into the body.

(a) $0.10 w t \%$

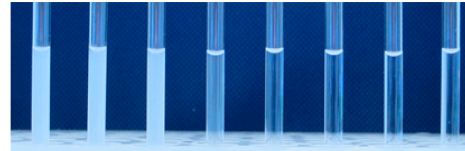

(b) $0.25 w t \%$

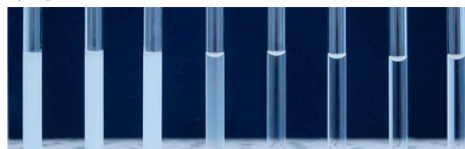

(c) $0.50 w t \%$

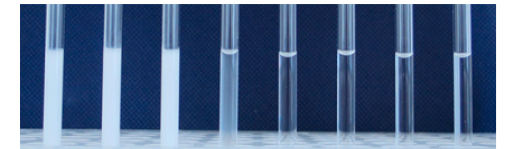

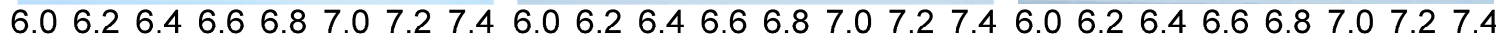 $\mathrm{pH}$ $\mathrm{pH}$ \\ $\mathrm{pH}$}

Figure 3. Phase transition behaviors of (a) $0.10 \mathrm{wt} \%$, (b) $0.25 \mathrm{wt} \%$, and (c) $0.50 \mathrm{wt} \%$ of the 40 mol\% DEGDMA-based microgel in $100 \mathrm{mM}$ phosphate buffer, $\mathrm{pH} 6.0$ to 7.4 with 0.2 increments at room temperature.

\subsection{NMR Relaxometric Properties at Neutral $p H$}

The transverse relaxation time $\left(T_{2}\right)$ of $0.50 \mathrm{wt} \%$ microgel suspensions was measured using a $43 \mathrm{MHz}{ }^{1} \mathrm{H}-\mathrm{NMR}$. In Group 1, $T_{2}$ was gradually reduced in the MBAA- and EGDMA-based microgels with decreasing $\mathrm{pH}$ (Figure $4 \mathrm{a}$ ). The reductions in $\mathrm{T}_{2}$ reached up to $0.3 \mathrm{~s}$ as the $\mathrm{pH}$ was adjusted from 7.4 to 6.0. Other polymers in Group 1 did not produce a significant reduction in $T_{2}$. On the other hand, Group 2 microgels showed sharp reductions in $T_{2}$ at $\mathrm{pH}$ 6.6-6.8, except for the $20 \mathrm{~mol} \%$ DEGDMA-based microgel (Figure $4 \mathrm{~b}$ ). The $T_{2}$ reductions caused by $40 \mathrm{~mol} \%$ and $45 \mathrm{~mol} \%$ DEGDMA-based microgels were 0.8 and $0.7 \mathrm{~s}$, respectively, in the narrow $\mathrm{pH}$ range of 6.4 to 6.8. The threshold $\mathrm{pH}$ of $T_{2}$ jump shifted from 6.2 to 6.6 with increasing cross-linking degree and correlated with the volume phase-transition behaviors (Figure $2 \mathrm{f}-\mathrm{h}$ ). These results demonstrated that the threshold $\mathrm{pH}$ can be adjusted by tuning the cross-linking degree and using an appropriate cross-linker according to the $\mathrm{pH}$ of the target region. A $T_{2}$-weighted MRI using a $1.5 \mathrm{~T}$ scanner showed that the microgel cross-linked with $40 \mathrm{~mol} \%$ DEGDMA produced significant changes in the MRI signal from $\mathrm{pH} 6.4$ to $\mathrm{pH} 7.4$ (Figure $4 \mathrm{~b}$ inset); this indicates that a $40 \mathrm{~mol} \%$ DEGDMA-based microgel can be a useful MRI sensor in detecting slight $\mathrm{pH}$ difference in pathologic tissue and normal tissue [12].
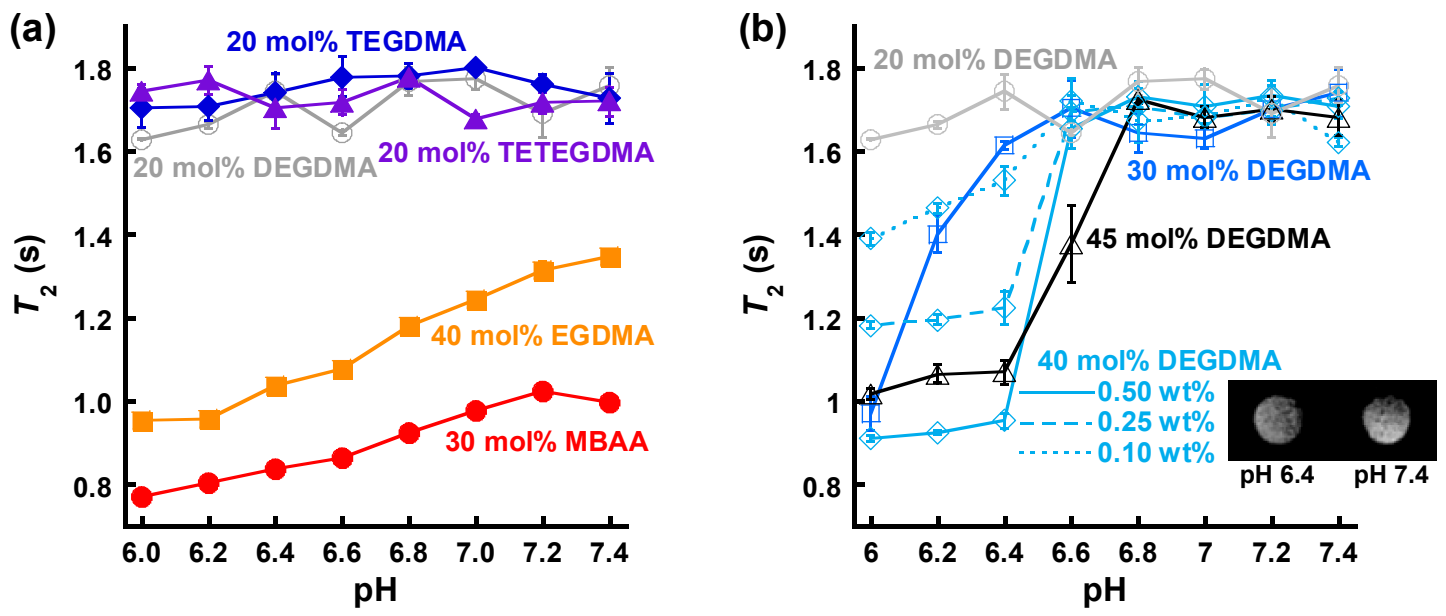

Figure 4. Transverse relaxation time $\left(T_{2}\right)$ of microgel suspensions of (a) Group 1 and (b) Group 2 in the $\mathrm{pH}$ range of $6.0-7.4$ at $28{ }^{\circ} \mathrm{C}$ (mean \pm standard error of the mean (SEM), $n=3$ ). The microgel cross-linked with $20 \mathrm{~mol} \%$ DEGDMA is shown in both figures. The inset in (b) is a $T_{2}$-weighted image of the $40 \mathrm{~mol} \%$ DEGDMA-based microgel in $100 \mathrm{mM}$ phosphate buffer ( $\mathrm{pH} 6.4$ and 7.4) at room temperature. [microgel] $=0.50 \mathrm{wt} \%$ unless otherwise noted. 
The phase transition depends on electrostatic repulsion of deprotonated carboxy groups and intramolecular attractive force such as van der Waals interactions of the side chains [24]. The higher degree of cross-linking can increase the intramolecular attractive force. As a result the phase transition $\mathrm{pH}$ shifted to a higher value than apparent $\mathrm{p} K_{\mathrm{a}}$ of non-cross-linked poly(methacrylic acid), which is around 6 [24]. The microgels cross-linked by $40 \mathrm{~mol} \%$ and $45 \mathrm{~mol} \%$ DEGDMA could have well-balance between hydrophilicity of the ethylene glycol moieties and hydrophobicity of the methyl groups to respond in the neutral $\mathrm{pH}$. On the other hand, the other cross-linkers were unlikely to be utilized to achieve this balance. TEGDMA and TETEGDMA formed a huge aggregate if their reaction stoichiometry was more than $30 \mathrm{~mol} \%$ because of their high reactivity. EGDMA and MBAA may be too short and less flexible to swell beyond the intramolecular attractive force.

The concentration dependence of $T_{2}$ was tested using 0.10 and $0.25 \mathrm{wt} \%$ suspensions of the $40 \mathrm{~mol} \%$ DEGDMA-based microgel (Figure $4 \mathrm{~b}$ ). The $0.25 \mathrm{wt} \%$ suspension showed a $T_{2}$ jump between $\mathrm{pH} 6.4$ and 6.6, which was similar to that of $0.50 \mathrm{wt} \%$ suspension. In contrast, the $0.10 \mathrm{wt} \%$ suspension showed moderate $T_{2}$ changes from $\mathrm{pH} 6.0$ to 6.6, although the phase transition $\mathrm{pH}$ was maintained at approximately 6.6 (Figure 3a). Therefore, $T_{2}$ reductions may be caused not only by volume phase transition but also by other $\mathrm{pH}$-dependent effects such as proton chemical exchange via functional side groups [25-27]. Group 1 and 2 microgel suspensions showed little changes in longitudinal relaxation time $\left(T_{1}\right)$ compared with the polymer-free buffer $\left(T_{1} \approx 2.8\right.$, data not shown) (Figure 5$)$. This could be due to the extremely slow motion of bound waters on the microgel surface [28-31].
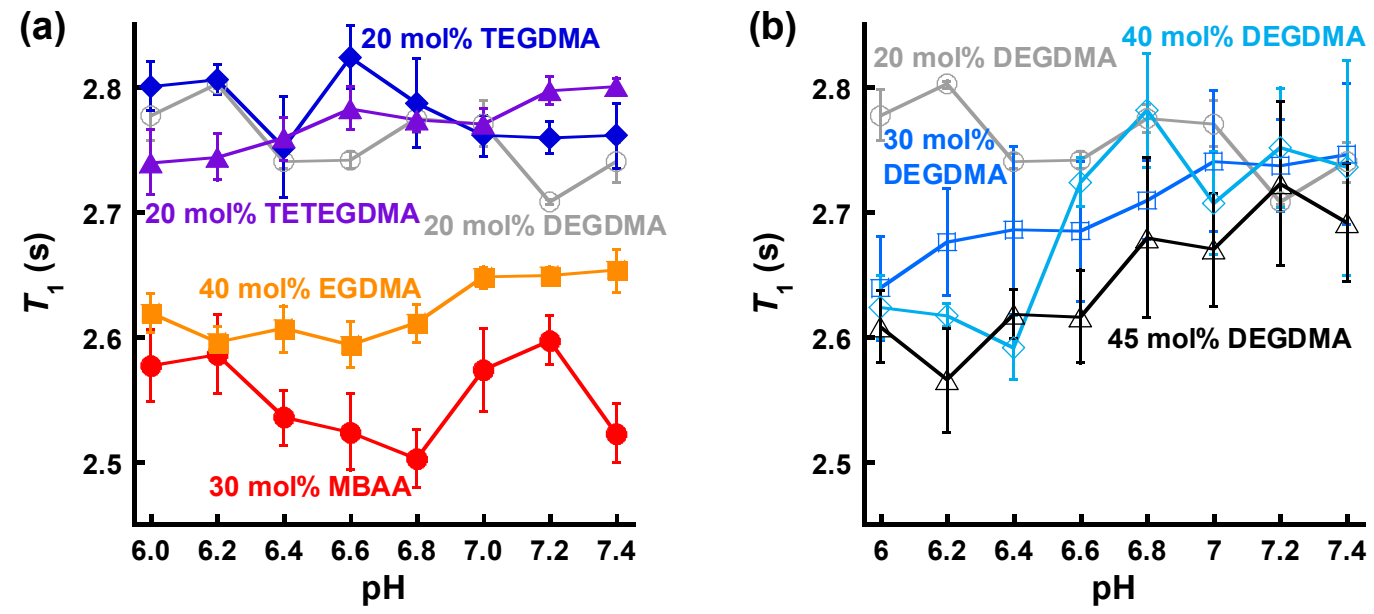

Figure 5. Longitudinal relaxation time $\left(T_{1}\right)$ of microgel suspensions of (a) Group 1 and (b) Group 2 in the $\mathrm{pH}$ range of $6.0-7.4$ at $28{ }^{\circ} \mathrm{C}$ (mean $\pm \mathrm{SEM}, n=3$ ). The microgel cross-linked with $20 \mathrm{~mol} \%$ DEGDMA is shown in both figures. [microgel] $=0.50 \mathrm{wt} \%$.

\section{Conclusions}

We demonstrated the development of the polymer microgels that undergo volume phase transition in the narrow range of neutral $\mathrm{pH}$ by tuning cross-linking conditions in precipitation polymerization. The microgels based on the appropriate cross-linkers and cross-linking degree caused substantial $T_{2}$ changes around the transition $\mathrm{pH}$. $T_{2}$-weighted MRI showed that the $40 \mathrm{~mol} \%$ DEGDMA-based microgel permits detection of a weakly acidic condition. This approach might be useful for producing a versatile platform, especially for the development of $\mathrm{pH}$-responsive MRI sensors. For future application, a conjugation with paramagnetic metal chelates and polymer encapsulation of magnetic nanoparticles would be potentially important in enhancing the sensitivity of sensors [32-36].

Supplementary Materials: The following are available online at http://www.mdpi.com/1424-8220/20/12/3367/s1: Supplementary Text: Longitudinal relaxation time $\left(T_{1}\right)$ and transverse relaxation time $\left(T_{2}\right)$., Table S1: Mean diameters of the microgels calculated from TEM images. 
Author Contributions: Conceptualization, S.O.; methodology, S.O. and S.Y.; validation, S.O., S.T. (Satoko Takayasu), S.T. (Shunsuke Tomita), Y.S. and S.Y.; formal analysis, S.O. and S.T. (Satoko Takayasu); investigation, S.O., S.T. (Satoko Takayasu), S.T. (Shunsuke Tomita), Y.S. and S.Y.; resources, S.O.; data curation, S.O.; writing-original draft preparation, S.O.; writing—review and editing, S.O., S.T. (Satoko Takayasu), S.T. (Shunsuke Tomita), Y.S. and S.Y.; visualization, S.O.; supervision, S.O.; project administration, S.O., S.T. (Shunsuke Tomita), Y.S. and S.Y.; funding acquisition, S.O., Y.S. and S.Y. All authors have read and agreed to the published version of the manuscript.

Funding: This work was supported by JST, PRESTO Grant Number JPMJPR1881, by JSPS KAKENHI Grant Numbers JP19K15719 and JP18H05985, and by the Research Foundation for Opto-Science and Technology, to S.O.

Acknowledgments: TEM was measured using a facility of NIMS microstructural characterization platform as a program of "Nanotechnology Platform" of the MEXT, Japan.

Conflicts of Interest: The authors declare no conflict of interest.

\section{References}

1. Gillies, R.J.; Liu, Z.; Bhujwalla, Z. ${ }^{31}$ P-MRS measurements of extracellular pH of tumors using 3aminopropylphosphonate. Am. J. Physiol. Cell Physiol. 1994, 267, C195-C203. [CrossRef]

2. $\quad$ van Sluis, R.; Bhujwalla, Z.M.; Raghunand, N.; Ballesteros, P.; Alvarez, J.; Cerdán, S.; Galons, J.-P.; Gillies, R.J. In vivo imaging of extracellular $\mathrm{pH}$ using ${ }^{1} \mathrm{H}$ MRSI. Magn. Reson. Med. 1999, 41, 743-750. [CrossRef]

3. Vermathen, P.; Capizzano, A.A.; Maudsley, A.A. Administration and ${ }^{1} \mathrm{H}$ MRS detection of histidine in human brain: Application to in vivo pH measurement. Magn. Reson. Med. 2000, 43, 665-675. [CrossRef]

4. Zhang, S.; Wu, K.; Sherry, A.D. A novel pH-sensitive MRI contrast agent. Angew. Chem. Int. Ed. 1999, 38, 3192-3194. [CrossRef]

5. Tóth, É.; Bolskar, R.D.; Borel, A.; González, G.; Helm, L.; Merbach, A.E.; Sitharaman, B.; Wilson, L.J. Water-soluble gadofullerenes: Toward high-relaxivity, $\mathrm{pH}$-responsive MRI contrast agents. J. Am. Chem. Soc. 2005, 127, 799-805. [CrossRef] [PubMed]

6. Aime, S.; Fedeli, F.; Sanino, A.; Terreno, E. A $R_{2} / R_{1}$ ratiometric procedure for a concentration-independent, pH-responsive, Gd(III)-based MRI agent. J. Am. Chem. Soc. 2006, 128, 11326-11327. [CrossRef]

7. Ali, M.M.; Woods, M.; Caravan, P.; Opina, A.C.L.; Spiller, M.; Fettinger, J.C.; Sherry, A.D. Synthesis and relaxometric studies of a dendrimer-based $\mathrm{pH}$-responsive MRI contrast agent. Chem. Eur. J. 2008, 14, 7250-7258. [CrossRef]

8. Okada, S.; Mizukami, S.; Kikuchi, K. Switchable MRI contrast agents based on morphological changes of pH-responsive polymers. Bioorg. Med. Chem. 2012, 20, 769-774. [CrossRef]

9. Mi, P.; Kokuryo, D.; Cabral, H.; Wu, H.; Terada, Y.; Saga, T.; Aoki, I.; Nishiyama, N.; Kataoka, K. A $\mathrm{pH}$-activatable nanoparticle with signal-amplification capabilities for non-invasive imaging of tumour malignancy. Nat. Nanotechnol. 2016, 11, 724-730. [CrossRef]

10. Botár, R.; Molnár, E.; Trencsényi, G.; Kiss, J.; Kálmán, F.K.; Tircsó, G. Stable and inert Mn(II)-based and pH-responsive contrast agents. J. Am. Chem. Soc. 2020, 142, 1662-1666. [CrossRef]

11. Raghunand, N.; Howison, C.; Sherry, A.D.; Zhang, S.; Gillies, R.J. Renal and systemic pH imaging by contrast-enhanced MRI. Magn. Reson. Med. 2003, 49, 249-257. [CrossRef] [PubMed]

12. Gillies, R.J.; Raghunand, N.; Garcia-Martin, M.L.; Gatenby, R.A. pH Imaging: A review of pH measurement methods and applications in cancers. IEEE Eng. Med. Biol. Mag. 2004, 23, 57-64. [CrossRef] [PubMed]

13. Ohta, H.; Ando, I.; Fujishige, S.; Kubota, K. Molecular motion and ${ }^{1} \mathrm{H}$ NMR relaxation of aqueous poly(N-isopropylacrylamide) solution under high pressure. J. Polym. Sci. B Polym. Phys. 1991, 29, 963-968. [CrossRef]

14. Sierra-Martín, B.; Romero-Cano, M.S.; Cosgrove, T.; Vincent, B.; Fernández-Barbero, A. Solvent relaxation of swelling PNIPAM microgels by NMR. Colloids Surf. A Physicochem. Eng. Asp. 2005, 270-271, 296-300. [CrossRef]

15. Okada, S.; Mizukami, S.; Matsumura, Y.; Yoshioka, Y.; Kikuchi, K. A nanospherical polymer as an MRI sensor without paramagnetic or superparamagnetic species. Dalton Trans. 2013, 42, 15864-15867. [CrossRef] [PubMed]

16. Li, W.-H.; Stöver, H.D.H. Mono- or narrow disperse poly(methacrylate-co-divinylbenzene) microspheres by precipitation polymerization. J. Polym. Sci. A Polym. Chem. 1999, 37, 2899-2907. [CrossRef] 
17. Goh, E.C.C.; Stöver, H.D.H. Cross-linked poly(methacrylic acid-co-poly(ethylene oxide) methyl ether methacrylate) microspheres and microgels prepared by precipitation polymerization: A morphology study. Macromolecules 2002, 35, 9983-9989. [CrossRef]

18. Bai, F.; Yang, X.; Huang, W. Preparation of narrow or monodisperse poly(ethyleneglycol dimethacrylate) microspheres by distillation-precipitation polymerization. Eur. Polym. J. 2006, 42, 2088-2097. [CrossRef]

19. Bai, F.; Huang, B.; Yang, X.; Huang, W. Synthesis of monodisperse poly(methacrylic acid) microspheres by distillation-precipitation polymerization. Eur. Polym. J. 2007, 43, 3923-3932. [CrossRef]

20. Liu, G.; Yang, X.; Wang, Y. Preparation of monodisperse hydrophilic polymer microspheres with $\mathrm{N}, \mathrm{N}^{\prime}$-methylenediacrylamide as crosslinker by distillation precipitation polymerization. Polym. Int. 2007, 56, 905-913. [CrossRef]

21. Li, G.; Yang, X.; Wang, B.; Wang, J.; Yang, X. Monodisperse temperature-responsive hollow polymer microspheres: Synthesis, characterization and biological application. Polymer 2008, 49, 3436-3443. [CrossRef]

22. Scranton, A.B.; Bowman, C.N.; Klier, J.; Peppas, N.A. Polymerization reaction dynamics of ethylene glycol methacrylates and dimethacrylates by calorimetry. Polymer 1992, 33, 1683-1689. [CrossRef]

23. Witte, J.; Kyrey, T.; Lutzki, J.; Dahl, A.M.; Houston, J.; Radulescu, A.; Pipich, V.; Stingaciu, L.; Kühnhammer, M.; Witt, M.U.; et al. A comparison of the network structure and inner dynamics of homogeneously and heterogeneously crosslinked PNIPAM microgels with high crosslinker content. Soft Matter 2019, 15, 1053-1064. [CrossRef]

24. Leyte, J.C.; Mandel, M. Potentiometric behavior of polymethacrylic acid. J. Polym. Sci. A 1964, 2, $1879-1891$. [CrossRef]

25. Kennan, R.P.; Richardson, K.A.; Zhong, J.; Maryanski, M.J.; Gore, J.C. The effects of cross-link density and chemical exchange on magnetization transfer in polyacrylamide gels. J. Magn. Reson. B 1996, 110, 267-277. [CrossRef]

26. Gochberg, D.F.; Kennan, R.P.; Maryanski, M.J.; Gore, J.C. The role of specific side groups and $\mathrm{pH}$ in magnetization transfer in polymers. J. Magn. Reson. 1998, 131, 191-198. [CrossRef] [PubMed]

27. Calucci, L.; Forte, C.; Gerges, I.; Ranucci, E. Effect of $\mathrm{pH}$ on water proton NMR relaxation in agmatine-containing poly(amidoamine) hydrogels. Langmuir 2009, 25, 2449-2455. [CrossRef]

28. Koenig, S.H.; Brown, R.D.; Ugolini, R. Magnetization transfer in cross-linked bovine serum albumin solutions at $200 \mathrm{MHz}$ : A model for tissue. Magn. Reson. Med. 1993, 29, 311-316. [CrossRef]

29. Yilmaz, A.; Ulak, F.S.; Batun, M.S. Proton $T_{1}$ and $T_{2}$ relaxivities of serum proteins. Magn. Reson. Imaging 2004, 22, 683-688. [CrossRef]

30. Yilmaz, A.; Budak, H.; Ulak, F.S. Determination of the effective correlation time modulating ${ }^{1} \mathrm{H}$ NMR relaxation processes of bound water in protein solutions. Magn. Reson. Imaging 2008, 26, 254-260. [CrossRef]

31. Calucci, L.; Forte, C.; Ranucci, E. Water/polymer interactions in poly(amidoamine) hydrogels by ${ }^{1} \mathrm{H}$ nuclear magnetic resonance relaxation and magnetization transfer. J. Chem. Phys. 2008, 129, 064511. [CrossRef] [PubMed]

32. Sun, Y.; Ding, X.; Zheng, Z.; Cheng, X.; Hu, X.; Peng, Y. Magnetic separation of polymer hybrid iron oxide nanoparticles triggered by temperature. Chem. Commun. 2006, 26, 2765-2767. [CrossRef]

33. Lattuada, M.; Hatton, T.A. Preparation and controlled self-assembly of Janus magnetic nanoparticles. J. Am. Chem. Soc. 2007, 129, 12878-12889. [CrossRef] [PubMed]

34. Zhou, L.; Yuan, J.; Wei, Y. Core-shell structural iron oxide hybrid nanoparticles: From controlled synthesis to biomedical applications. J. Mater. Chem. 2011, 21, 2823-2840. [CrossRef]

35. Paquet, C.; de Haan, H.W.; Leek, D.M.; Lin, H.-Y.; Xiang, B.; Tian, G.; Kell, A.; Simard, B. Clusters of superparamagnetic iron oxide nanoparticles encapsulated in a hydrogel: A particle architecture generating a synergistic enhancement of the $T_{2}$ relaxation. ACS Nano 2011, 5, 3104-3112. [CrossRef] [PubMed]

36. Okada, S.; Mizukami, S.; Sakata, T.; Matsumura, Y.; Yoshioka, Y.; Kikuchi, K. Ratiometric MRI sensors based on core-shell nanoparticles for quantitative $\mathrm{pH}$ imaging. Adv. Mater. 2014, 26, 2989-2992. [CrossRef] [PubMed]

(C) 2020 by the authors. Licensee MDPI, Basel, Switzerland. This article is an open access article distributed under the terms and conditions of the Creative Commons Attribution (CC BY) license (http://creativecommons.org/licenses/by/4.0/). 